\title{
ALEXANDRE FRADIQUE MORUJÃO ${ }^{1}$
}

\author{
Carlos Morujão \\ Universidade Católica Portuguesa
}

\section{Pequena resenha biográfica}

Alexandre Fradique Morujão nasceu a 25.11.1922, em São Paio de Vizela, no concelho de Guimarães. Concluiu em 1947 a licenciatura em Engenharia Eletrotécnica, pela Faculdade de Engenharia da Universidade do Porto. Em 1954, concluiu a licenciatura em Ciências Histórico-Filosóficas, na Faculdade de Letras da Universidade de Coimbra, com a defesa da tese A Doutrina da Intencionalidade na Fenomenologia de Husserl. Das «Investigações Lógicas» às «Meditações Cartesianas», sendo aprovado com a classificação de 18 valores. Em 1956-57 frequentou, na Universidade de Colónia, os seminários dos Professores Volkman-Schluck e Ludwig Landgrebe (este último assistente de Husserl na Universidade de Freiburg), assim como, sob a orientação deste último e de Walter Biemel, naqueles mesmos anos, toma um contacto mais aprofundado com o pensamento do autor das Ideias para uma Fenomenologia Pura e uma Filosofia Fenomenológica iniciando-se no trabalho de investigação dos inéditos husserlianos, nos Husserl-Archiv anexos àquela Universidade. Em 1957-58 trabalhou ainda, sob a orientação dos Professores Van Breda e Rudolf Boehm, nos Archives-Husserl da Universidade de Lovaina. Em 31.07.1961 termina as provas de doutoramento na Universidade de Coimbra, com a defesa da tese Mundo e Intencionalidade. Ensaio

\footnotetext{
${ }^{1}$ Para a elaboração deste ensaio servimo-nos, parcialmente, de dois trabalhos anteriores. A «Introdução» a A. F. Morujão, Estudos Filosóficos. Lisboa: Imprensa Nacional-Casa da Moeda, 2002, vol. I, pp. 7-16, e uma conferência que proferimos no âmbito do curso de Mestrado em Filosofia Ibérica, realizado pelo Departamento de Filosofia da Faculdade de Ciências Humanas da UCP, no ano letivo de 2004-2005.
} 
sobre o Conceito de Mundo na Fenomenologia de Husserl. A 12.02.1971 foi aprovado em concurso para Professor Catedrático do Grupo de Filosofia da Universidade de Coimbra.

A atividade letiva de A. F. Morujão repartiu-se pela Universidade de Coimbra, pela Universidade Católica Portuguesa e, episodicamente, pela Universidade dos Açores, ao abrigo de convénios entre esta Universidade e a Universidade coimbrã. No ano académico de 1997-98, terminou a sua carreira docente, orientando, na Faculdade de Ciências Humanas da Universidade Católica, em Lisboa, o seminário de licenciatura subordinado ao tema «O conceito de substância na filosofia moderna, de Descartes a Kant». Durante mais de quarenta anos de docência universitária lecionou, sobretudo, as disciplinas de Lógica, de Filosofia Moderna e de Filosofia Contemporânea; os seus interesses filosóficos abrangeram áreas e temáticas tão diferentes como a fenomenologia (sobretudo na sua vertente husserliana), as filosofias da existência, o pensamento de Kant e a filosofia portuguesa (sendo, nesta última área, de destacar, acima de tudo, os ensaios dedicados a Sampaio Bruno e a Leonardo Coimbra).

\section{Características gerais da obra}

Boa parte da investigação filosófica de Alexandre Fradique Morujão é, sem dúvida, uma investigação orientada para a docência universitária, ou resultante dessa mesma docência, inscrevendo-se ou não nessas etapas obrigatórias do percurso académico que se traduzem na elaboração de dissertações. É um destino comum a grande parte do pensamento filosófico contemporâneo, para o bem e para o mal. E se ninguém ousará afirmar que o que de mais significativo um Husserl ou um Heidegger, por exemplo, escreveram, consiste nas suas teses universitárias, não é menos certo que a simples consulta dos inéditos, hoje na sua maioria acessíveis em edições rigorosas, mostra como, sem esse material em parte destinado à docência, não teríamos hoje, pelo menos na forma em que as conhecemos, obras tão fundamentais como Ser e Tempo ou Lógica Formal e Lógica Transcendental.

A atividade filosófica de um professor de filosofia não se esgota, naturalmente, nos seus escritos, nem, tão pouco, nos conteúdos que, nas aulas, transmitiu a várias gerações de alunos. Há qualquer coisa que nenhuma recolha dos escritos poderá transmitir, nem sequer uma que, como a que a Imprensa Nacional-Casa da Moeda pôs recentemente à disposição do leitor português, procure recolher algum desse material de que se faz o que, vulgarmente, chamamos «preparação de aulas». Tudo isso, que ficou por escrever e, quantas vezes, por dizer, é o que constitui, em boa medida, o enigma que é sempre 
alguém com quem travámos conhecimento; as inflexões na voz, o estilo, a disponibilidade, as impaciências. Destas coisas faz-se também, como sabemos, o trabalho universitário.

Num interessante ensaio intitulado «Um método de trabalho universitário: o regime de seminário» ${ }_{2}^{2} \mathrm{~A}$. F. Morujão produz um notável conjunto de reflexões sobre o modo como encarava a docência e pensava que esta se deveria exercer. Não desprezando a importância de que se pode revestir o curso magistral (mesmo nas suas modalidades consagradas de aula teórica e de aula prática) - enquanto forma de transmissão dos aspetos essenciais de uma dada problemática, ou das teses e dos comentários mais pertinentes sobre uma determinada matéria do curriculum universitário - é clara a sua preferência pelo regime de seminário, única forma de verdadeira iniciação na atividade científica. Aí, um pouco como o aprendiz de uma arte mecânica na oficina do mestre, o aluno é iniciado, não com preleções, mas através de uma prática e de um exemplo vivos, na verdadeira atividade de fazer filosofia.

Não é possível filosofar, ou sequer pensar, fora da língua e sem atender às significações que a língua veicula. Tal implica, porém, ao mesmo tempo, a necessidade de verter para a própria língua aquilo que foi pensado noutras, pois o próprio nunca se basta a si mesmo e o Selbstdenker - aquele que ousa pensar por si, para nos servirmos da bela expressão de Kant - é aquele que, afinal, pensa com todos. Nesta perspetiva, a tradução para português (em colaboração com Maria Manuela dos Santos) da Crítica da Razão Pura e o excelente estudo introdutório que a acompanha, pondo à disposição dos estudantes e investigadores nacionais uma das obras mais marcantes da filosofia europeia, não foi apenas um acontecimento de relevo no panorama editorial nacional; foi também, da parte de A. F. Morujão, um ato filosófico de longo alcance e, por isso, um ato de cultura. Não seria inoportuno relembrarmos, a este propósito, os termos em que Hegel se exprime num projeto de carta ao filólogo Johann Heinrich Voss, tradutor de Homero para alemão: um povo permanece bárbaro e não considera como propriedade sua as coisas excelentes que conhece, enquanto não aprender a conhecê-las na sua própria língua. ${ }^{3}$

$\mathrm{Da}$ intensa atividade intelectual de A. F. Morujão, no domínio da filosofia, há ainda que destacar a colaboração em diversas enciclopédias, bem como as inúmeras recensões publicadas em revistas da especialidade. Elas dão conta, pela diversidade dos temas e dos autores abordados, de um contacto

${ }^{2}$ Agora acessivel em Estudos Filosóficos. Lisboa, Imprensa Nacional-Casa da Moeda, 2004, vol. II, pp. 135-141. (De agora em diante referir-nos-emos a esta edição, em dois volumes, pela sigla EF; indicaremos em algarismos romanos o volume e em algarismos árabes a página.)

${ }^{3}$ Estas palavras de Hegel são reproduzidas por A. F. Morujão no final da sua Introdução à tradução portuguesa da Crítica da Razão Pura. Agora em EF II, 291. 
assíduo com a tradição filosófica do ocidente, muito mais alargado do que aquele que poderia transparecer da leitura das obras e dos ensaios publicados. Destacaríamos, de todo este trabalho, acima de tudo, as entradas na Enciclopédia Logos. Se, por um lado, da simples consulta do índice desta obra poderia resultar a impressão de uma excessiva dispersão, pouco propícia a uma abordagem rigorosa da totalidade dos assuntos tratados, fácil será constatar, pela leitura, que tal impressão não corresponde, na globalidade, ao valor efetivo do trabalho produzido. Este, pelo contrário, dá conta de um estudo direto (e quase sempre na língua original) dos autores ou dos temas em causa, bem como da bibliografia científica mais atualizada e mais exigente a seu respeito.

\section{Os temas principais e a inspiração inicial}

A compreensão do pensamento filosófico de um autor é, em boa medida, facilitada pelo conhecimento daqueles que escolheu como seus interlocutores privilegiados. No caso de Alexandre Fradique Morujão, o facto de ter sido Edmund Husserl a desempenhar esse papel - pois foi a ele que dedicou os seus mais significativos e originais ensaios filosóficos - é revelador, não só de uma certa ideia de filosofia, mas também de um modo de fazer filosofia a que o autor se manteve fiel ao longo da vida. Porém, esta inspiração husserliana talvez não tenha sido a que desencadeou em A. F. Morujão a motivação inicial para o filosofar. É nele extremamente forte - e pensamos também que claramente percetível, para quem souber ler - a presença de diversos temas e problemas do filósofo espanhol Ortega y Gasset, de tal modo que é, por vezes, em linguagem orteguiana que são apresentadas algumas ideias de Husserl. (Tarefa facilitada, em todo o caso, pelo facto de Ortega ter sido um razoável conhecedor do pensamento husserliano, como se pode comprovar pela leitura do seu interessante «Prólogo para alemães», que deveria introduzir, em 1934, a tradução para alemão de um conjunto de textos seus, mas que nunca chegou a ser publicada.) Tanto quanto sabemos, pois tal nos foi confidenciado por alguns antigos alunos, a presença de Ortega foi sempre extremamente forte na lecionação do autor, quer a nível dos cursos de licenciatura, quer, sobretudo, a nível dos mestrados. Mas, para quem necessitar de evidência textual, aconselhamos a leitura de «Que é a Filosofia?» ${ }^{4}$ e um pequeno exercício de comparação: entre o modo como é apresentado o significado da dúvida cartesiana e o que por Ortega é dito sobre o mesmo assunto na Lição VII de ¿Qué es Filosofia?; ou entre a interpretação que é fornecida da noção filosófica de mundo - aliás explicitamente chamado «circunstância» - e o que diz Ortega nas três

${ }^{4}$ A. F. Morujão, "Que é a Filosofia?". EF II, 17-43. 
últimas lições de ¿Qué es Filosofia?, ou então na Lição V de Unas Lecciones de Metafisica. A mesma evidência textual se poderia também encontrar, com outra finura de análise, na leitura de alguns parágrafos de Mundo e Intencionalidade. Este será um assunto a que voltaremos ainda na secção final deste ensaio.

Regressemos a Husserl. A. F. Morujão não tardará a reconhecer que a definição da análise fenomenológica como um processo de evidenciação ${ }^{5}$ não faz senão proclamar o carácter indissociável do método da filosofia e do seu tema próprio. Já em $A$ Doutrina da Intencionalidade na Fenomenologia de Husserl, mas, com mais força e uma outra profundidade, em Mundo e Intencionalidade, mostrará como, para Husserl, a filosofia, mesmo nos seus começos, não se assemelha a uma ciência relativamente imperfeita, que se iria aperfeiçoando por uma espécie de progresso natural. Pelo contrário, o sentido da filosofia é já percetível no radicalismo do seu ato fundador, na sua vontade em elucidar de uma maneira absoluta. É, pois, pelo seu método que a fenomenologia é ciência em sentido radical: ela é a ciência de todas as origens, sem cujo estudo as restantes ciências não ultrapassariam o estado de ingenuidade, ao mesmo tempo que constitui uma conexão teorética unitária de proposições, fundada numa evidência última.

Que, por outro lado, tenha sido, sobretudo, a última fase do pensamento husserliano a interessá-lo, ou seja, aquela fase marcada por obras como as Meditações Cartesianas ou A Crise das Ciências Europeias, mas também, convém não esquecê-lo, Lógica Formal e Lógica Transcendental; que mesmo a análise, sempre rigorosa, das Investigações Lógicas ou de Ideias I (não mencionando já as escassas referências a A Filosofia da Aritmética, por exemplo), tenha sido feita, segundo pensamos, antes de mais, em função de temas que só na última fase do pensamento husserliano ganharam o seu significado pleno; tudo isto nos dá uma ideia do tema que unifica, quanto a nós, não só os estudos husserlianos de A. F. Morujão, mas também uma boa parte dos seus mais significativos ensaios sobre outras áreas da filosofia: a saber, o tema do mundo. O autor parece, assim, compartilhar a tese de Gaston Berger, aliás por si expressamente referida em $A$ Doutrina da Intencionalidade na Fenomenologia de Husserl, segundo a qual cada novo avanço da fenomenologia não é previsível a partir dos trabalhos anteriores, ${ }^{6}$ sendo só ao nível das inves-

${ }^{5}$ Cf. Mundo e Intencionalidade. Coimbra: Universidade de Coimbra, 1961, p. 53.

${ }^{6}$ A Doutrina da Intencionalidade na Fenomenologia de Husserl. Coimbra (Separata de Biblos, XXX), 1955, pp. 128-129. Cf. Gaston Berger, Le Cogito dans la Philosophie de Husserl. Paris : Aubier, 1941, pp. 65-66. Veremos, no decurso deste ensaio, como a interpretação, por A. F. Morujão, de Filosofia como Ciência de Rigor confirma o que acabámos de dizer. 
tigações últimas que adquirem o seu pleno significado as investigações que marcaram a sua fase inicial.

Alguns textos, como por exemplo, «Sobre a Fenomenologia Husserliana», incluído no conjunto de estudos intitulado Subjetividade e História, ${ }^{7}$ indiciam ainda a importância de um outro tema husserliano que recebeu um tratamento menos exaustivo nos textos publicados, a saber, o da relação entre a natureza subjetiva primordial, aquela em que assenta a descrição do que é realmente percecionado, e a perceção do outro. ${ }^{8}$

Esta questão parece ter interessado especialmente A. F. Morujão, nomeadamente quando Husserl parece recusar a esta perceção um simples carácter analogizante com a experiência do corpo próprio, parecendo antes conferir-lhe o carácter de uma aperceção direta da vida da consciência do outro e do seu corpo como um corpo animado.

\section{Mundo e Intencionalidade. Análise dos temas principais}

Mundo e Intencionalidade, publicado em 1961, subintitulado «Ensaio sobre o conceito de mundo na fenomenologia de Husserl», constituiu originalmente, como dissemos, a tese de doutoramento de A. F. Morujão, apresentada à Faculdade de Letras da Universidade de Coimbra. A obra estrutura-se em quatro grandes capítulos, subdivididos em parágrafos, num total de 26, incluindo o da Conclusão; os capítulos intitulam-se, respetivamente, «O mundo natural e o problema da sua fundamentação», «A estrutura da subjetividade transcendental», «Do eu transcendental à intersubjetividade» $\mathrm{e}$ «O problema fenomenológico do mundo»; inclui ainda uma Introdução, uma Conclusão e uma Bibliografia. A esta estrutura subjaz uma determinada interpretação do sentido e do alcance da fenomenologia, de que iremos dando conta nas linhas que se seguem.

${ }^{7}$ A. F. Morujão, "Sobre a Fenomenologia Husserliana". In: Subjectividade e História. Coimbra: Universidade de Coimbra, 1969, pp. 105-139, Esta obra era composta por três textos relativamente independentes, um dos quais, aliás, reformulando e ampliando um artigo anteriormente publicado, tendo a sua existência em forma de livro ficado unicamente a dever-se às necessidades de um concurso universitário para Professor Extraordinário da Faculdade de Letras da Universidade de Coimbra. Por tal motivo, pareceu oportuno ao organizador da edição dos Estudos Filosóficos apresentar os ensaios que a compunham como textos independentes, como efetivamente o foram na sua génese.

${ }^{8}$ Esta afirmação baseia-se, como é óbvio, numa apreciação puramente quantitativa. Convém não esquecer os três densos parágrafos consagrados a esta questão em Mundo e Intencionalidade, ed. cit., pp. 164-191. A análise aí levada a cabo, contudo, apoia-se fundamentalmente em Meditações Cartesianas, e não na grande quantidade de importantes textos, à data ainda inéditos (classificados nos Arquivos Husserl da Universidade de Lovaina com a letra $E$ ), que Husserl consagrou a este assunto. 
A Introdução a Mundo e Intencionalidade afirmava-o explicitamente: a estrutura e o sentido do mundo é o verdadeiro tema da meditação husserliana, mas a noção de intencionalidade conduz Husserl a uma peculiar ideia de mundo. Assim, segundo A. F. Morujão, Husserl não se limitou a recuperar para a filosofia um tema que, para a filosofia da segunda metade do século XIX e dos inícios do século $\mathrm{XX}$, marcada pelos avanços do positivismo, não representava significado algum, mas impediu também que o seu completo esclarecimento se pudesse fazer nos quadros conceptuais da antiga cosmologia racional. ${ }^{9}$ Como se sabe, em Husserl, todas as «transcendências» - ou seja, tudo aquilo que a consciência, prisioneira da atitude natural, considera como existindo realmente fora de si - são afetadas pelo índice de suspensão; não se nega a sua existência, mas deixa-se, filosoficamente, de dela fazer uso. Uma vez que a existência não traz determinação intelectual alguma - na linguagem de Kant: não é um predicado real, mas sim simples posição - é admissível suspender todos os juízos de existência e proceder a uma análise do modo como o objeto nos é dado: totalmente e de maneira imediata, parcialmente e sob forma perspetivística, em forma de presença exaustiva ou de presença inexaustiva.

Mas esta renúncia à maneira ingénua de considerar o mundo não equivale a uma sua perda. ${ }^{10}$ Pelo contrário, o mundo é recuperado como fenómeno de mundo, ou seja, como correlato de uma vivência intencional. É neste sentido que a velha questão da omnitudo realitatis adquire, com a fenomenologia, uma nova dimensão, só possibilitada pela abertura ao domínio transcendental: o mundo não é mais uma coleção de objetos que se constituem transcendentalmente, pois transformou-se numa presença sob a forma de horizonte, não totalmente transparente à função constituinte da consciência. Assim, qualquer objeto (incluindo o que por tal é designado na terminologia da lógica formal) só poderá ser alvo de uma atividade cognoscitiva a partir de um mundo previamente dado. ${ }^{11}$

${ }^{9}$ Mundo e Intencionalidade, ed. cit., p. 14.

10 “O fenómeno puro, ponto de partida da fenomenologia de Husserl". In: Subjetividade e História. Coimbra: Universidade de Coimbra, 1969, pp. 13-40, p. 34. Cf. com a afirmação das Cartesianische Meditationen: "é preciso primeiro perder o mundo, graças à epoché, para o recuperar seguidamente na auto reflexão universal" (Husserliana, Band I. Den Haag: Martinus Nijhoff, 1950, p. 138), citada em “O fenómeno puro...", ed. cit., pp. 39-40.

${ }^{11}$ Mundo e Intencionalidade, ed. cit., p. 249. É claro que poderíamos ainda perguntar se Husserl não se limitará, pura e simplesmente, no final da vida, a restaurar a noção de omnitudo realitatis tal como a recebera da tradição, ao definir o mundo na Krisis der europeischen Wissenschaften (Beilage XXV), como "substrato de todos os substratos". A discussão deste problema ultrapassa, como é obvio, os modestos limites que nos impusemos nesta apresentação. 
Neste sentido, a fenomenologia, tal como Husserl a entende, apesar das suas semelhanças com o projeto cartesiano - no qual o próprio Husserl reconhecerá uma primeira formulação de uma ciência dos princípios, a que todas as ciências empíricas teriam de recorrer para obter os seus fundamentos últimos -, não se encontra, tal como este, na mesma dependência relativamente à ideia de ciência típica da idade moderna. A base da fenomenologia, como A. F. Morujão acentuara já na sua dissertação de licenciatura, não é apenas o ego cogito, mas uma tomada de consciência de si mesmo, plena, inteira e universal, ${ }^{12}$ ou seja, do eu na sua relação com os outros eus (que não são constituídos por si ao mesmo título que os entes intramundanos), numa pluralidade de mónadas que se temporaliza e espacializa num mundo objetivo comum. O eu completo revela-se, assim, como uma totalidade, ${ }^{13}$ isto é, não apenas como um pólo de identidade, mas também como um conjunto de Habitualitäten (conjunto de sínteses já realizadas, persistindo passivamente na vida do eu e modificando-a), situado num mundo pressuposto por cada cogitatio como o que a ela serve de pano de fundo em que o sentido se evidencia. Por este motivo, o acesso à conceção fenomenológica de mundo (tema do capítulo IV de Mundo e Intencionalidade) ter-se-ia de fazer por meio de um esclarecimento da estrutura da subjetividade transcendental e do movimento próprio da atividade constitutiva e dos seus níveis de realização. Será este um assunto a que voltaremos ainda na secção seguinte.

É aquela característica de horizonte, que é própria do mundo, que o pensamento husserliano, na sua última fase, se encarregará de explorar. Em 1929, em Lógica Formal e Lógica Transcendental, com a noção de «a priori material sintético», Husserl mostrará como todo o objeto existente é, afinal, um existente num universo de existências, que possibilita a sua determinação material concreta. Em Experiência e Juizo, Husserl, elaborando uma genealogia do juízo predicativo, defenderá que a evidência do juízo, fundada na evidência dos objetos, remete para uma experiência de objetos individuais que pressupõe o mundo como terreno universal de crença. ${ }^{14}$

É este carácter radical do mundo como fenómeno, portador de uma legitimidade primeira e absoluta, não tendo necessidade de coisa alguma para ser fundada, que transforma ainda a fenomenologia em ciência das origens, ou dos «primeiros princípios». Fazendo aparecer o mundo na sua realidade imanente à consciência, mostrando a ligação essencial entre a consciência e o mundo, a fenomenologia permite ver como todos os conhecimentos remetem para um

\footnotetext{
${ }^{12}$ A Doutrina da Intencionalidade na Fenomenologia de Husserl, ed. cit. pp. 120-121.

${ }^{13}$ Mindo e Intencionalidade, ed. cit., p. 188.

${ }^{14}$ Mundo e Intencionalidade, ed. cit., pp. 20-21, e a totalidade dos $\S \S 21$ e 22, pp. 201-223.
} 
sujeito, para a atividade constituinte de uma consciência, que funciona como origem, suporte e fundamento do seu sentido. ${ }^{15}$

Mas em Husserl, como sabemos, o problema da intencionalidade é também o problema da perceção e da estrutura temporal da consciência percetiva. Em Mundo e Intencionalidade, no $\S 6$, intitulado "O ser como consciência e o ser como realidade", apoiando-se nos principais textos de Ideias I acerca deste assunto, Alexandre Morujão fornece-nos uma excelente análise dessa estrutura temporal da consciência, graças à qual o objeto real se constitui num fluxo ininterrupto de vivências, nas quais se dá de maneiras sempre diversas e em perspetivas sempre diferentes, sem, com isso, perder o seu carácter de polo de identidade da visada intencional. ${ }^{16}$ Assim, toda a análise concreta de um objeto percecionado - por exemplo, o livro que se encontra em cima da minha secretária enquanto trabalho - mostra que o «momento agora», em que o perceciono ao colocá-lo à minha frente para o ler, se encadeia no «momento que acabou de passar», em que o percecionei do lado esquerdo da folha de papel em que então escrevia. Tenho, contudo, a consciência da existência corporal de um só e mesmo livro, embora tenham variado os pontos de vista sobre ele. A. F. Morujão cita, ${ }^{17}$ a este propósito, uma passagem do $\S 41$ de Ideias I que nos parece valer igualmente a pena transcrever:

[...] constantemente, o agora da perceção se transforma na consciência que se lhe encadeia do acabado de passar e, de imediato, reluz um novo agora, etc. Tal como a coisa percecionada em geral, também tudo o que lhe pertence, como partes, lados, momentos, é, pelos mesmos motivos, necessariamente transcendente à perceção, chamem-se-lhes qualidades primárias ou secundárias. ${ }^{18}$

É aquela variação que funciona como a marca da transcendência do objeto relativamente à consciência que o visa; ou seja, retomando o exemplo de há pouco, ela é a prova de que o livro percecionado não é nenhum ingrediente real da minha perceção dele, mas que, pelo contrário, ele se encontra aí, diante de mim, num mundo de objetos independente da estrutura da minha consciência. Ora, se o mundo é o correlato da consciência e, ao mesmo tempo, o terreno de toda a posição de crença, mesmo não sendo objeto de uma perceção evidente, sendo a partir dele que se exprime a atividade constitutiva da subjetividade transcendental, não é possível que, para Husserl, esse mesmo

${ }^{15}$ A Doutrina da Intencionalidade na Fenomenologia de Husserl, ed. cit. p. 36.

${ }^{16}$ Cf. Mundo e Intencionalidade, ed. cit., pp. 71 e ss. (O autor reenvia para os $\$ \S 38,40$ e 41 de Ideias I.) No mesmo sentido, "O fenómeno puro, ponto de partida da fenomenologia de Husserl", ed. cit., pp. 25 e ss.

${ }^{17}$ Ibid., p. 72, nota 2.

${ }^{18}$ Hussel, Ideias I, Hua III, pp. 92-93. 
mundo não seja determinado temporalmente, de acordo com a constituição intrínseca da consciência intencional. ${ }^{19}$

\section{O problema da intencionalidade}

$\mathrm{Na}$ sua primeira formulação, nas Investigações Lógicas, a noção de intencionalidade desempenha duas funções na filosofia de Husserl. Ela serve, em primeiro lugar, para definir os fenómenos psíquicos, no sentido de atos de consciência. ${ }^{20}$

Um dos inconvenientes da definição de Brentano consistia, justamente, no facto de a intencionalidade ser tratada como um acontecimento do mundo, como um facto mundano, ${ }^{21}$ servindo como carácter distintivo de uma região do mundo - a dos fenómenos psíquicos - relativamente a outra, a dos fenómenos físicos. No $\S 5$ De Mundo e Intencionalidade, A. F. Morujão faz uma breve referência às origens medievais do conceito. ${ }^{22}$ Há, quanto a nós, um «exemplarismo» husserliano, para nos exprimirmos em linguagem escolástica, na sua conceção da intencionalidade, que tem seguramente raízes medievais, graças à influência da filosofia de Franz Brentano. Este exemplarismo, sem referência aos seus eventuais antecedentes medievais (ou seja, toda a tradição platónica que vai de Santo Agostinho a Duns Escoto), foi claramente explicitado por A. F. Morujão, em «A reflexão sobre a história na fenomenologia de Husserl», um dos três estudos inicialmente incluídos em Subjetividade e História, nos termos seguintes:

[...] entre o objeto individual e fáctico e a essência há uma relação eidética que implica que todo o objeto individual possua um fundo eidético, a sua essência e, reciprocamente, que a toda a essência corresponda uma série de indivíduos, representando a sua exemplificação fáctica $[. . .]^{23}$

${ }^{19}$ Em O Problema da História na Fenomenologia de Husserl (Separata de Perspetivas da Fenomenologia de Husserl). Coimbra: Centro de Estudos Fenomenológicos, 1965, p. 5, n. 1, o autor anuncia a preparação de um estudo sobre os problemas da temporalidade e da historicidade em Husserl e em Heidegger, que nunca chegou a levar a cabo, e onde, certamente, estas questões seriam desenvolvidas. Aquele ensaio foi reelaborado e publicado, em 1969, com o título "A reflexão sobre a história na fenomenologia de Husserl". In: Subjetividade e História, ed. cit., pp. 41-104, mas já sem a referida nota.

${ }^{20}$ Logische Untersuchungen, Hua XIX/I, p. 380.

${ }^{21}$ Mundo e Intencionalidade, ed. cit., p. 67

22 Ibid., p. 67.

${ }^{23}$ Subjetividade e História, ed. cit. p. 44 (agora em EF I, 400). Existindo, num número felizmente diminuto de casos, mais do que uma versão do mesmo texto, por vezes, apenas, com pequeníssimas alterações no título ou no conteúdo, o organizador da edição de Estudos Filosóficos, optou, regra geral, pela publicação da primeira versão. Não hesitou, contudo, em publicar mais do que uma quando a quantidade das alterações introduzidas pareceu 
O que daqui nos parece que se deverá concluir é que a essência se relaciona com o objeto individual como causa exemplar e não como generalidade abstrata. Por este motivo, não será difícil detetar algumas relações entre a fenomenologia e diversas correntes não-tomistas da filosofia escolástica. Seria possível encontrar semelhanças com a teoria da intencionalidade de certos nominalistas do século XIV, como Pierre Auréol ou Guilherme de Occam, ou até mesmo com a cognitio intuitiva de Duns Escoto. Mas este assunto, tanto quanto sabemos, não parece ter interessado particularmente A. F. Morujão, ou mesmo a generalidade dos investigadores portugueses que se interessaram pela fenomenologia husserliana.

Husserl insistiu no facto de, com o termo intencionalidade, não se estar a falar de uma relação entre certos acontecimentos de ordem psicológica (as vivências intencionais) e certas existências reais (chamadas objetos), nem, tão pouco, de uma relação psicofísica que tivesse lugar na realidade objetiva. ${ }^{24}$ Se nos situarmos no plano estritamente fenomenológico - ou seja, se realizarmos a redução fenomenológica -, teremos apenas em consideração a essência das vivências e aquilo que lhes pertence segundo uma necessidade incondicionada. Ora, é de acordo com uma lei de essência que, na sua estrutura, qualquer vivência se revela como sendo «consciência de...». Como dirão, mais tarde, as Meditações Cartesianas, a palavra intencionalidade designa a particularidade fundamental da consciência que consiste em trazer em si, como cogito, o seu cogitatum. ${ }^{25}$ Não espantará, por isso, que a fenomenologia só se interesse pela intencionalidade da consciência na medida em que esta reflete sobre si mesma, e não enquanto se transcende ingenuamente em direção ao mundo objetivo, ou se considera, não menos ingenuamente, como uma parte desse mundo. ${ }^{26}$ Mas nem por isso na consciência intencional a coisa deixa de estar «aí», inteiramente dada. É por isso que existe um realismo husserliano ${ }^{27}$ - e aqui seguimos de muito perto as análises de A. F. Morujão em Mundo e

significativa. Para o caso em apreço, registe-se a existência de duas versões do mesmo texto, apresentando diferenças em número suficiente para justificar uma publicação em separado. Temos, assim, "O problema da história na fenomenologia de Husserl"», publicado nas Atas do Primeiro Colóquio Português de Fenomenologia, Coimbra, 1965, e "A reflexão sobre a história na fenomenologia de Husserl", publicado em 1969 em Subjetividade e História. Foi esta última versão que utilizámos; a passagem que transcrevemos não se encontra na primeira versão deste ensaio.

${ }^{24}$ Cf. Ideias I, Hua III, p. 80; cit. em Mundo e Intencionalidade, ed. cit., p. 68, notas 3 e 4.

${ }^{25}$ Cf. Hua I, p. 7; cit. em Mundo e Intencionalidade, ed. cit., p. 69.

${ }^{26}$ Cf. André de Muralt, «Les deux dimensions de l'intentionnalité husserlienne". In: La Métaphysique du Phénomène. Paris : Vrin, 1985, pp. 10-24, p. 11.

${ }^{27}$ Não iremos aqui desenvolver toda a problemática das relações entre realismo e idealismo em Husserl. Chamamos apenas a atenção para o que, a este respeito, é dito em Mundo e Intencionalidade, ed. cit., pp. 243 e ss. 
Intencionalidade - perfeitamente compatível com uma teoria da imanência, em que a ideia de representação, no sentido clássico do termo, não tem mais sentido. Esta imanência, contudo, não constitui nenhum topos metafísico, ou seja, nenhuma alma-substância, mas apenas o plano em que tudo aparece (ou se dá, se preferirmos esta linguagem), seja na forma de presença exaustiva, seja na de presença inexaustiva. ${ }^{28}$

Mas a noção de intencionalidade, nas Investigações Lógicas, servia também a Husserl (contra Ernst Mach) para distinguir o aparecimento do objeto do objeto aparecente, tratando-se de perceber que o aparecimento é uma vivência e não algo que aparece do mesmo modo que o objeto. ${ }^{29}$ Tratava-se, então, de uma questão polémica, mas dada já como adquirida em Ideias $I$ e, por isso, apresentada sem tais intuitos, como na obra de 1901. A análise de A. F. Morujão, centrada na obra de 1913, não confere excessiva importância a esta questão. ${ }^{30}$

Curiosamente, Husserl nega que as sensações - ou o que, na linguagem de Ideias I, chamaríamos os «dados hiléticos» (sons, cores, etc.) - tenham um carácter intencional, o que não deixa de ter consequências não menos curiosas, pois significa admitir-se que na base da experiência de um objeto ao qual nos dirigimos intencionalmente está qualquer coisa que não é ainda da ordem da intencionalidade. Outros fenomenólogos portugueses, como Maria Manuela Saraiva, chamaram também a atenção para este aspeto. ${ }^{31}$ É todo o problema do que, mais tarde, Husserl desenvolverá sob a designação de sínteses passivas, ou seja, o plano em que, antes da atividade sintética que se exprime na síntese judicativa, são dados à razão os materiais com que trabalha nos planos superiores de atividade do espírito. Reenviando para uma passagem de Lógica Formal e Lógica Transcendental, a obra que Husserl publica em 1929 e que para alguns constitui o seu livro mais importante, A. F. Morujão comenta:

Estes materiais, relativamente à atividade constituinte da síntese racional, são dados, mas não em absoluto, pois igualmente foram constituídos; a vida da consciência não pode ser rompida; o sentido de qualquer transcendência não pode ser outro que o de uma evidência intencional produzida no sujeito da consciência. A constituição pela atividade pressupõe uma camada inferior, uma passividade que recebe o objeto e o encontra completamente feito. Mas analisando melhor 0 objeto, reconhecemo-lo como resultado de uma génese passiva. Tudo o que se

${ }^{28}$ Cf. Husserl, Logische Untersuchungen, Hua XIX/1, pp. 365-366. Mundo e Intencionalidade, ed. cit., p. 127.

${ }^{29}$ Husserl, ibid., p. 359.

${ }^{30}$ Em todo o 2. ${ }^{\circ}$ capitulo de Mundo e Intencionalidade, ed. cit., pp. 55-135 (\$§ 4-13), dedicada à compreensão das estruturas da consciência intencional, contámos apenas duas referências à 5. Investigação Lógica, onde a questão é abordada pela primeira vez por Husserl.

${ }^{31}$ Cf. Manuela Saraiva, L'Imagination selon Husserl, ed. cit., p. 27. 
nos apresenta, por exemplo, uma coisa real, abstraindo de todos os seus caracteres "espirituais", é dada como coisa de uma maneira original na síntese da experiência passiva. ${ }^{32}$

Mas, no ensaio de 1980 intitulado «Significado e estrutura da redução fenomenológica», após uma primeira citação do Manuscrito husserliano FI 17: «A fenomenologia põe fora de circuito a realidade da natureza, mesmo a realidade do céu e da terra, dos homens e dos animais, do próprio eu e do eu alheio, mas retém, por assim dizer, a alma, o sentido de tudo isto ${ }^{33}$ procedendo, de seguida, a uma análise dos $\S \S 36$ e 85 de Ideias I, A. F. Morujão comenta: a vida, para Husserl, é pensada a partir da intencionalidade; ela anima os objetos, mas também os dados hiléticos desprovidos de intencionalidade, tornando-os igualmente intencionais, quer dizer, dirigidos para os objetos. ${ }^{34}$ Husserl, com efeito, defendera que nem todos os momentos reais de uma vivência intencional eram, eles próprios, intencionais, ou seja, nem todos possuíam o carácter de ser «consciência de qualquer coisa»». ${ }^{35}$ Assim, nas vivências que, na sua totalidade, se apresentam como intencionais, dever-se-ão distinguir, de acordo com o mestre de Freiburg, duas camadas ou níveis diferentes: um momento sensual e, sobre ele, um momento «espiritual» doador de sentido e propriamente constitutivo do objeto. ${ }^{36}$

\section{Significado e alcance da «viragem transcendental»}

Está em causa, neste conjunto de questões, uma interpretação global do significado da fenomenologia husserliana e da sua evolução, nomeadamente, o significado da chamada «viragem transcendental» do pensamento de Husserl, de que a primeira manifestação seriam as lições de Göttingen de 1907, publicadas postumamente no volume II da Husserliana com o título de A Ideia de Fenomenologia. Sobre este assunto, as interpretações divergem, não sendo este o local para discutir em profundidade as opiniões em confronto. Dois textos de Alexandre F. Morujão deverão agora reter a nossa atenção: Mundo e Intencionalidade, naturalmente, mas também «Significado e estrutura da redução fenomenológica». $\mathrm{O}$ autor parece defender, no $\S 13$ de

${ }^{32}$ Mundo e Intencionalidade, ed. cit., p. 127. Cf. Formale und transzendentale Logik, p. 208.

${ }^{33}$ Cf. EF I, 457

${ }^{34}$ Ibid., p. 471

${ }^{35}$ Cf. Ideias I, Hua III, p. 81.

${ }^{36}$ No $\S 85$ das Ideias (Hua III, p. 209), Husserl chama ao primeiro momento eine formlose Stoff (uma matéria desprovida de forma) e ao segundo eine stofflose Form (uma forma desprovida de matéria). 
Mundo e Intencionalidade - um dos mais notáveis de todo o livro, em nosso entender-, que aquela viragem mais não fez do que revelar, de uma forma mais precisa do que acontecia nas Investigações Lógicas, a intencionalidade como a essência mesma da consciência, ou seja, o facto de esta existir «segundo um modo de ser que se esgota na visada de algo diferente». ${ }^{37}$ Contudo, já o $\S 8$, ao analisar o significado das reduções fenomenológicas, antecipava esta conclusão. Com a epoché - diz-se aí -, apesar de o mundo material, de Deus e das esferas ideais da lógica e da matemática terem sido já postas «fora de circuito», a consciência permanece ainda mundana, sobre ela não se pratica ainda nenhuma espécie de redução, e o nível a que se situa Descartes no final da sua $2 .^{a}$ Meditação não é ainda verdadeiramente ultrapassado. ${ }^{38}$ Uma nova redução deverá ser operada, tendo agora como alvo a consciência psicologicamente reduzida, em ordem a se alcançar, para lá de todas as alterações reais ou possíveis das vivências, a identidade absoluta que as unifica numa única e mesma corrente. Só neste momento surge essa transcendência na imanência que constitui o eu transcendental.

Por outras palavras, com a sua viragem transcendental Husserl exprimiria com a clareza desejada o facto de a imanência de que falámos mais atrás não ser nenhuma interioridade, nem nenhuma perceção interna (como era em Brentano, devedor da psicologia de Stuart Mill e de Herbert Spencer), mas sim, apenas, a garantia da evidência pura do que é dado, evidência não contaminada por nenhuma crença existencial, nem por nenhum juízo de existência. Esta interpretação, que se aproxima significativamente da de Sartre, em «A transcendência do ego» (que não é, contudo, citado na passagem que estamos a comentar), recusa a esta unidade imanente as características de um eu ao modo da filosofia crítica. As sucessivas reduções, procedendo por purificação da vida consciente e por inibição de toda a transcendência, não têm outro propósito que não seja o de desvelar a atividade anónima da intencionalidade, não tematizada a nível da atitude natural. ${ }^{39}$ Pois tal atitude não consiste numa unidade sintética da aperceção segundo o modelo kantiano, ou seja, de uma unidade ordenada à síntese do diverso, no juízo. Pelo contrário, o problema fundamental de Husserl - pelo menos no quadro de Ideias Ié o da relação entre a infinitude das intenções atuais e potenciais e a síntese completa das experiências possíveis de um objeto, como polo de identidade. Será também esta a opinião de René Schérer, em obra posterior a Mundo e

${ }^{37}$ Mundo e Intencionalidade, ed. cit., p. 127.

${ }^{38}$ Em Mundo e Intencionalidade, p. 94, nota 3, A. F. Morujão cita em apoio desta tese Erste Philosophie, II, Hua VIII, p. 140.

${ }^{39}$ Mundo e Intencionalidade, ed. cit., p. 126. 
Intencionalidade, ${ }^{40}$ embora contestada por intérpretes mais recentes do pensamento husserliano, como, por exemplo, Jocelyn Benoist.

Nos $\S \S 15$ e 16 de Mundo e Intencionalidade, assim como em O Problema da História na Fenomenologia de Husserl, o autor analisa a estrutura temporal da consciência constituinte e o modo como nela, segundo Husserl, se dá a constituição originária do tempo. Sai do nosso propósito uma análise detalhada destas questões, sem dúvida das mais complexas de toda a fenomenologia. Note-se, no entanto, que elas parecem representar, para A. F. Morujão, o culminar do projeto fenomenológico husserliano, na medida em que abrem um pensamento que, na sua formulação inicial, era predominantemente estático e estrutural, à dimensão da génese e da história. Como se fosse justamente na reflexão sobre a história, no duplo sentido em que esta pode ser entendida - ou como historicidade do indivíduo, que traduz a dimensão ontológica do homem, ou como sentido oculto do encaminhamento histórico do ser humano na sua totalidade -, que a fenomenologia de Husserl ganhasse, finalmente, toda a sua pertinência e atualidade. Como se só nela se cumprisse a intenção inicial de Husserl de uma fundamentação radical da filosofia na subjetividade transcendental, e nela ganhassem todo o seu sentido as duas operações que se encontram na base do método fenomenológico: a redução e a constituição. ${ }^{41}$

O problema do modo de ser do eu e da sua estrutura temporal não é, por isso, um problema ocioso. Já nas modalidades primitivas da vida intencional - no percecionar que presentifica - se surpreende aquele fluir contínuo a que chamamos tempo. O tempo é, portanto, a forma da consciência como tal, de modo que toda a constituição do objeto tem como ingrediente mais geral o tempo. ${ }^{42}$ Não faz, então, qualquer sentido perguntar pelo modo de ser do eu fora das modalidades temporais em que ele se torna presente para si mesmo; a única questão que tem sentido pôr é a de o que é o eu, como centro vivo ou condição de possibilidade de presentificação.

Assim, para A. F. Morujão, só a «viragem transcendental» confere o seu pleno sentido à crítica da atitude natural com a qual a fenomenologia, desde os seus inícios, delimitou o âmbito próprio da sua investigação. Só ela dá

${ }^{40}$ Cf. La Phénoménologie des «Recherches Logiques» de Husserl (trad. cast. Madrid: Gredos, 1969, p. 249). A análise de René Schérer parece-nos a nós estar em profunda sintonia com a de A. F. Morujão, no $\S 13$ de Mundo e Intencionalidade, inclusive no que diz respeito ao carácter transcendental do eu, após 1907. Analisando as correções e aditamentos de Husserl à 2. edição das Investigações Lógicas (em particular à 5. Investigação), nota o comentador francês que só a redução, com a sua abertura ao plano transcendental, permite compreender a verdadeira natureza do eu, se o identificar, ou com a unidade de um mero fluxo de vivências, ou com uma transcendência no sentido de uma «coisa».

${ }^{41}$ O Problema da História na Fenomenologia de Husserl, ed. cit., pp. 5-6.

42 "Sobre a Fenomenologia Husserliana". In: Subjetividade e História, ed. cit., p. 122. 
seguimento à exigência de uma fundamentação absoluta, sem a qual a filosofia não saberia ser uma ciência de rigor. Na verdade, nenhum homem de ciência, por meios puramente científicos - o físico por meios puramente físicos, ou o historiador por meios puramente históricos -, saberá dar conta da essência própria do terreno em que assenta a sua investigação. Por natureza, as ciências aceitam a existência de certas realidades, bem como o carácter inteligível delas. ${ }^{43}$ As ciências operam com conceitos cujo significado e sentido nunca foi plenamente esclarecido, uma vez que lhes escapa a dimensão puramente subjetiva e inobjetivável da vida transcendental da consciência reduzida, onde significado e sentido têm a sua génese.

\section{A intersubjetividade. Fenomenologia e filosofias da existência}

Um outro núcleo de problemas diz respeito à questão da intersubjetividade. Podemos detetar o interesse de A. F. Morujão por esta questão, quer nos seus estudos sobre Husserl, quer nos estudos sobre Gabriel Marcel, ${ }^{44}$ quer, embora com menor evidência, nos seus estudos sobre Kant. Mas ainda no seu último ensaio sobre o filósofo de Königsberg, "O Sentido da Finalidade na Filosofia de Kant", ${ }^{45}$ analisando a função do juízo de gosto e do juízo teleológico na economia da $3 .^{a}$ Crítica, A. F. Morujão procurava mostrar como ambos se inscrevem no projeto kantiano de constituição de uma visão unificada do mundo (uma Weltanschauung), possibilitada pelo acordo universal entre todos os sujeitos pensantes. A constituição de uma teoria da intersubjetividade transcendental, superadora dos limites impostos pela Crítica da Razão Pura e pela Crítica da Razão Prática ao exercício do pensar, forneceria, assim, ao projeto kantiano o seu acabamento sistemático.

Duvidamos, contudo, da possibilidade em aproximar o pathos existencial subjacente às análises de Marcel da fidelidade ou do compromisso, por

${ }^{43}$ Cf. Philosophie als strenge Wissenschaft, Frankfurt am Main: V. Kostermann, 1965, pp. 20-21; cit. em "A filosofia como saber rigoroso de fundamentação", EF I, 477-495, p. 482 , nota 17 .

44 No artigo citado na nota anterior (p. 132), A. F. Morujão faz eco da tese de Klaus Held, segundo o qual a doutrina husserliana da intersubjetividade, a monadologia transcendental da 5. "Meditação Cartesiana e de tantas páginas inéditas, permitiriam aproximar o pensamento de Husserl sobre esta matéria com a filosofia do existencialista francês. No mesmo sentido, Mundo e Intencionalidade, ed. cit., p. 177, nota 2. Todavia, em "A intersubjetividade em Gabriel Marcel" (EF II, 449-464), não é feita qualquer menção à teoria da intersubjetidade em Husserl.

${ }^{45}$ A. F. Morujão, "O Sentido da Finalidade na Filosofia de Kant". In: Pensar a Cultura Portuguesa, Homenagem a Francisco da Gama Caeiro. Lisboa: Edições Colibri / Departamento de Filosofia da Faculdade de Letras da Universidade de Lisboa, 1993, pp. 377-389. 
exemplo, e o tom de extrema sobriedade que anima as descrições husserlianas de comportamentos semelhantes. Tal não nos impedirá, ainda assim, de reconhecer a pertinência do reconhecimento de «crescentes preocupações de carácter existencialista» ${ }^{46}$ no Husserl mais tardio, nomeadamente naquele que escreve os textos recolhidos postumamente por Ludwig Landgrebe em Experiência e Juizo. A redução fenomenológica não seria mais do que o procedimento metodológico que, pondo em suspenso, quer os produtos da elaboração científica, quer as elaborações inconscientes e pseudo-científicas do homem comum, nos daria acesso à experiência primordial do existir. ${ }^{47}$

Husserl sentira, como é sabido, a necessidade de um reajustamento da redução transcendental, ao notar que na esfera egológica há índices de objetividades que se reportam a subjetividades alheias, quer dizer, que não podem ser vistas como meros corpos materiais, mas sim como corpos organizados fisiologicamente e governados psiquicamente. Quer dizer, há um certo tipo de objetividades que só posso percecionar como sendo sujeitos que visam um mundo tal como eu, e que, simultaneamente, me visam. Ora, se, de acordo com a fenomenologia, o meu ego transcendental é o fundamento primeiro de tudo aquilo que para mim vale como $\operatorname{ser}^{48}$ não terão as alteridades dos outros egos, assim como a natureza intersubjetiva, ou natureza comum, em que todos vivemos, de ser concebidas em relação a mim e, por conseguinte, como constituídas por mim quanto ao seu sentido de ser? A questão, então, é: qual o sentido da intencionalidade em que, com base no meu próprio ego, se forma em mim o sentido do eu do outro? Não sendo o outro um simples correlato intencional, como se poderá constituir um outro sujeito constituinte, para esse sujeito constituinte que eu sou?

Mas, sendo claro que o eu alheio nunca é dado na sua ipseidade, mas sim como alter ego, será necessário recorrer aqui a uma experiência analógica (e que, no entanto, como Husserl sublinha, não é analógica no sentido vulgar do termo), ${ }^{49}$ ou seja, a uma transposição percetiva do meu próprio ser, mediante a qual, partindo do meu corpo, de que me sirvo, de que disponho na medida em que atuo, um outro corpo aparece como o corpo de que um outro eu igualmente se serve e dispõe. É através dele que nos aparece o eu do outro, que nos

${ }^{46}$ A. F. Morujão, "Em torno do existencialismo", EF II, 463-486, p. 474.

${ }^{47} \mathrm{Ibid}$. Neste texto, que poderemos considerar de juventude uma vez que é datado de 1954 , alguns temas husserlianos parecem-nos a nós ser compreendidos à luz da interpretação de Merleau-Ponty, aliás expressamente citado, por mais do que uma vez, em notas de rodapé.

48 A Doutrina da Intencionalidade na Fenomenologia de Husserl (Separata de Biblos, XXX). Coimbra, 1955, p. 107.

${ }^{49}$ Cf. Mundo e Intencionalidade, ed. cit. p. 167, bem como os textos de Husserl para os quais aí se remete. 
é inacessível em original. Por outras palavras, de acordo com a análise muito clara que deste difícil problema é feita em Mundo e Intencionalidade: ${ }^{.0}$ ao corpo do outro, que, a mim, me é dado como um «aí» - mas que a esse outro eu é dado como um «aqui», em torno do qual a totalidade da natureza se organiza -, corresponde uma constituição da natureza que é idêntica à que se constitui na minha esfera primordial. Alteraram-se, apenas, na passagem de mim para o outro, as perceções efetivas, não a estrutura da totalidade das perceções possíveis e seus correlatos noemáticos.

Em «O problema da intersubjetividade na fenomenologia de Husserl», A. F. Morujão dedica a esta questão uma investigação aprofundada, comentando a interpretação de Klaus Held da expressão husserliana wie wenn ich dort wäre («como se eu aí estivesse»). ${ }^{51}$ Como, além disso, observa A. F. Morujão, para o mestre de Freiburg, ao mundo da experiência correspondem certos conteúdos que, pelos seus predicados espirituais, remetem para sujeitos estranhos a cada um de nós e à nossa intencionalidade constituinte individual. São os chamados objetos culturais (obras de arte, monumentos, a própria linguagem), quer dizer, objetividades que se reportam, direta ou indiretamente, a subjetividades alheias. Assim, tanto o mundo das coisas como o das objetividades ideais transforma-se em mundo intersubjetivamente constituído. Husserl dirá, em Cartesianische Meditationen, que é graças à intencionalidade constituinte comum do conjunto dos eus, ou mónadas individuais, que se constitui um só e mesmo mundo. 52 Nesta via, a fenomenologia, essa "secreta nostalgia da filosofia europeia" como the chamara Husserl em 1910, em A Filosofia como Ciência de Rigor, revela-se capaz de recuperar, num plano estritamente fenomenológico, as verdades metafisicas dos grandes sistemas idealistas, em particular, o do idealismo alemão, mas também todos aqueles temas que as filosofias ideológicas, tão veementemente combatidas no artigo de 1910, formularam sob a pressão das exigências do momento.

\section{Os problemas fenomenológicos do «mundo da vida»}

Julgamos ser agora claro que, apesar da finura das análises levadas a cabo em Mundo e Intencionalidade, o interesse de Alexandre F. Morujão se dirigiu mais, como afirmámos no início, para a conceção husserliana de mundo e suas implicações, do que para a conceção husserliana da natureza do ato percetivo. Julgamos, também, que a análise do tema do mundo é levada a cabo

\footnotetext{
${ }^{50}$ Ibid., pp. 178-185.

${ }^{51}$ Agora em EF I, 497-519.

52 Cartesianische Meditationen, ed. cit., p. 137.
} 
a partir de uma orientação que foi recebida numa prévia leitura de Ortega y Gasset. Por este motivo, a dívida de Alexandre F. Morujão para com Ortega deve ser de novo aqui assinalada, tanto mais que, quase no início da sua atividade docente, as conferências radiofónicas, orteguianamente intituladas «Que é a filosofia?», já mencionadas na secção 3 deste ensaio, se revelarão como um elemento chave para a compreensão do seu pensamento e das particularidades da sua abordagem da filosofia do autor das Investigações Lógicas.

Vejamos, para começar, de que modo se pode realizar a rutura fenomenológica com a tese natural da existência do mundo. Uma das vias apontadas por Husserl para efetuar esta rutura tem o seu ponto de partida da constatação de que todo o eu empírico que sustenta um ato de perceção está interessado no ser do objeto percecionado. Mas, para além deste eu, podemos imaginar um eu, sobreposto ao primeiro, que reflete sobre ele, que participa do interesse dele e que, tal como ele, duvida, acredita, etc. (Exemplificando: quando reflito sobre a minha perceção de uma casa, nem por isso deixo de participar na crença de que existe a casa que eu perceciono.) Porém, podemos supor ainda um terceiro eu, que considera a perceção do primeiro de uma forma desinteressada, que não executa a crença na existência do objeto percecionado, mas considera a natureza do puro ato percetivo, enquanto ato subjetivo dotado de um conteúdo imanente..$^{53}$

A esta via, é possível contrapor, como «processo subsidiário», a via cartesiana ${ }^{54}$ ou seja, aquela que parte da dúvida, embora o faça com intenções diferentes das de Descartes. Pois, ao invés do que acontecia com Descartes, parte dela, não para descobrir a radical dependência do sujeito que duvida relativamente ao Deus verdadeiro, garantia última da verdade objetiva das ideias, mas sim para encontrar no sujeito um campo imanente de experiências fenomenológicas. A realidade das coisas, mais além da que têm como ideias nossas, é problemática e, no melhor dos casos, derivada da que têm como conteúdo da nossa consciência. A consciência está sempre consigo própria, é ao mesmo tempo, para nos servirmos de uma expressão de Ortega, o inquilino e a casa ${ }^{55}$ Mas esta tese idealista tem algo de paradoxal, ela é o resultado de uma reviravolta na maneira de pensar o universo, consequência do que o filósofo espanhol chamava, em ¿Qué es Filosofia?, o «heroísmo filosófico». ${ }^{56}$ Seja-nos permitido seguir, por mais alguns momentos, o pensamento do autor:

Há algo de sobremaneira estranho nesta tese idealista e é o seu ponto de partida, o descobrimento da subjetividade como tal, do pensamento na sua interioridade.

\footnotetext{
${ }^{53}$ Mundo e Intencionalidade, ed. cit., nota 2 à p. 57, p. 59

${ }^{54}$ Ibid., p. 57.

${ }^{55}$ Ortega y Gasset, ¿Que es Filosofia?, ed. cit., p. 170.

${ }^{56}$ Ibid., p. 171, p. 170.
} 
Porque dá-se o caso de o homem antigo desconhecer por completo este modo de ser subjetivo, reflexivo, íntimo e solitário. ${ }^{57}$

Sigamos agora o que diz A. F. Morujão em Mundo e Intencionalidade: normalmente, a expressão «vejo um objeto» significa o mesmo que «creio que esse objeto é real»; mas a esta maneira normal posso contrapor uma não normal - ou seja, praticando o tal «heró́smo filosófico» de que fala Ortega -, na medida em que desligo o meu eu reflexivo dessa crença a que ele não se encontra obrigatoriamente ligado. «Filosofar não é viver, mas sim esvaziar-se» - desasirse, diz o filósofo espanhol, um sugestivo termo que é uma tradução de um termo alemão empregue por Husserl - «conscientemente das crenças vitais». ${ }^{8}$ Por seu lado, diz A. F. Morujão nas conferências intituladas «Que é a filosofia?»:

Certo é que a dúvida, psicologicamente entendida [...], pertence ao mesmo estrato das crenças; está-se na dúvida como se está na crença, embora esta última, no dizer de Ortega y Gasset, seja a terra firme e o duvidoso "uma realidade líquida onde o homem não se pode sustentar e cai". É nesse oco das nossas crenças que é a dúvida, que as ideias fazem a sua intervenção e depois se consolidam em novas crenças. [...] Certo é que, a todo o momento, surgem dúvidas, mas limitadas a um determinado âmbito e superadas em seguida; mas uma dúvida universal é psicologicamente inexequível. Todavia, sem esta problematização universal a filosofia é uma pretensão vã. ${ }^{59}$

Em ¿Qué es Filosofia?, obra que, como já o demos a entender, influenciou sobremaneira A. F. Morujão, Ortega apresenta este problema do seguinte modo. O que há de mais primitivo, aquilo de que não podemos duvidar e que fundamenta todo o conhecimento por inferência, são os dados do universo. Toda a dificuldade consiste em determinar que dados serão esses. Será que pertencem a tais dados últimos os átomos ou os eletrões de que nos falam os físicos? Facilmente constatamos que a sua existência depende de uma teoria, tratando-se, por isso, de uma verdade inferida ou derivada. ${ }^{60}$

Em sentido husserliano, a dúvida universal visa a omnitudo realitatis, cuja evidência é problemática, pois é igualmente problemática a evidência dos objetos que a integram. ${ }^{61} \mathrm{O}$ mundo natural não se caracteriza por ser uma evi-

${ }^{57}$ Ibid., p. 171.

${ }^{58}$ Ibid., p. 151. Cf. Mundo e Intencionalidade, ed. cit., $\S 4$, p. 55: em virtude da «tese» geral do mundo, tomamos o mundo circundante como uma realidade existente.

59 A. F. Morujão, "Que é a filosofia?", EF II, 23-24.

${ }^{60}$ Ortega y Gasset, op. cit., pp. 146-149. Toda a Lição VII desta obra de Ortega poderia ser comparada com o $\S 4$ de Mundo e Intencionalidade; descobrir-se-iam, por certo, interessantes afinidades.

${ }^{61}$ Mundo e Intencionalidade, ed. cit., p. 198. 
dência apodítica (ver Ideen $I, \S \S 48-49$ ), na medida em que os objetos que o compõem podem não convergir numa sucessão de experiências, ou em que uma certa experiência se pode transformar, posteriormente, numa falsa aparência. Enquanto correlato da atitude natural ou científica, o mundo, assim, é um dubitandum. O mundo é apenas o correlato de um conjunto de experiências, sendo, por isso, uma ideia, supondo nós que todos os sujeitos podem, de direito, fundir num único mundo intersubjetivo todas as suas experiências atuais.

Assim, poder-se-ia perguntar: onde se manifesta e se me revela o problema do mundo? Qual o terreno de donde parto em busca do ser do mundo, de Deus e do homem? Onde descubro a resposta para o problema do conhecimento e da cultura? A resposta, diz A. F. Morujão, nas mesmas conferências que referimos há pouco, terá de ser: na existência humana, na vida humana, ou seja, na minha vida. «A minha vida dá-se sempre como supremo continente, suprema categoria que; de qualquer modo, faz possível a relação das coisas comigo mesmo».6. $\mathrm{A}$ uma leitura atenta, apesar do tom fortemente orteguiano, parecem existir também algumas semelhanças com o procedimento, a que alguns chamam «regressivo», de Husserl, em Experiência e Jutzo. Trata-se de descobrir, por detrás das operações lógico-formais da consciência judicativa, o plano pré-lógico em que elas se enraízam; trata-se, por outras palavras, de desvendar, por detrás das realizações lógicas sedimentadas nas nossas práticas quotidianas e na nossa relação ingénua com o mundo, ou seja, por detrás do mundo tal como o herdámos em virtude do trabalho de constituição de sentido das gerações que nos precederam, o mundo da intuição e da experiência imediata. O espaço exato da geometria, o tempo exato da física, as leis causais em que assentam as nossas ciências da natureza, são já o resultado de um processo que Husserl chama de «idealização». Tal significa que eles não são, nem o espaço, nem o tempo, nem o mundo, originários e reais, em que todos vivemos sem tematizar. ${ }^{63}$ Este universo de ser, que é o das ciências naturais e exatas, constitui como que uma roupagem lançada sobre o mundo da intuição e da experiência imediata. É a este mundo que todos os resultados da ciência vão buscar o seu sentido último, e o esquecimento desta relação fundamental com o mundo leva a tomar pelo verdadeiro ser todo um conjunto de ideias que resultam de tomadas de decisão de carácter metodológico, motivadas por interesses de natureza cognitiva.

Ora o mundo da aritmética, por exemplo, só se encontra disponível para mim quando faço aritmética; a esfera do mundo científico-natural só se me

${ }^{63}$ Mundo e Intencionalidade, ed. cit., p. 214. 
torna acessível se estudar a natureza do ponto de vista das ciências físico-matemáticas. Mas o mundo da vida está sempre disponível. «As ciências de factos só originam homens de factos.» Quer dizer, prisioneiros dos factos e das suas relações, mas incapazes de perceber o seu sentido. A vida mundana tem a mesma factualidade. Trata-se de aceder ao mundo da vida. As ciências de factos afastam-se da vida e não basta que a filosofia se transforme, à maneira kantiana, numa reflexão transcendental sobre a possibilidade de conhecimento nessas ciências para se aceder a um domínio mundano-vital que não se encontre já afetado pelas idealizações científicas. ${ }^{64}$ Foi em reação a isto que o homem passou a buscar as orientações para a vida em doutrinas irracionalistas. ${ }^{65}$

\section{Bibliografia fundamental ${ }^{66}$}

1954 A Doutrina da Intencionalidade na Fenomenologia de Husserl. Das Investigações Lógicas às Meditações Cartesianas. Coimbra: Coimbra Editora.

1954 "Em torno do existencialismo". Estudos, XXXVII(VI-VII).

1957 "O «Fenómeno puro», ponto de partida da fenomenologia de Husserl". Filosofia, IV.

1961 Mundo e Intencionalidade. Ensaio sobre o Conceito de Mundo na Feno-menologia de Husserl. Coimbra: Universidade de Coimbra.

1969 Subjetividade e História. Coimbra: Universidade de Coimbra.

1980 "Significado e Estrutura da Redução Fenomenológica. Biblos, LVI.

1981 "Fenómeno, Númeno, Coisa-em-si. Notas sobre três Conceitos Kantianos. Revista Portuguesa de Filosofia, XXXVII.

1982 "A filosofia como saber rigoroso de fundamentação". Atas do Primeiro Congresso Luso-brasileiro de Filosofia, Revista Portuguesa de Filosofia, XXXVIII.

1985 "O Problema da Intersubjetividade na Fenomenologia de Husserl". Atas do 2. ${ }^{\circ}$ Colóquio Português de Fenomenologia, Revista Portuguesa de Filosofia, XL.

1988 "Estrutura e sentido do «mundo da vida»". Revista Portuguesa de Filosofia, XLIV.

1989 "Ciência e filosofia no pensamento de Leonardo Coimbra". In: AA.VV., O Pensamento Filosófico de Leonardo Coimbra. Lisboa: Edições Didaskalia, pp. 57-73.

1993 "O Sentido da Finalidade na Filosofia de Kant". In: AA.VV., Pensar a Cultura Portuguesa. Lisboa: Colibri.

${ }^{64}$ Ibidem, p. 216.

${ }^{65}$ Sobre este assunto, $c f$. Alexandre F. Morujão, "Estrutura e sentido do mundo da vida", EF, pp. 521-534.

${ }^{66}$ Os textos são indicados por ordem cronológica e a partir da edição original. 


\begin{abstract}
This paper addresses the meaning and importance of Alexandre Morujão's work for the reception of husserlian phenomenology in the Portuguese university. It gives also an overall view of his philosophical activity and interests, either as a university professor and researcher, or as a translator of philosophical works. The paper tracks also some of philosophical influences, sometimes hidden in the author's published works, such as the influence of the Spanish philosopher Ortega y Gassett. Regarding phenomenology (and especially husserlian phenomenology), the paper shows that Alexandre Morujão's work tried to highlight the following three main themes: 1) the radical character of phenomenological attitude, as the science of origins and as a unitary theoretical connection of propositions grounded in ultimate evidences; 2) the ensuing radical awareness of the phenomenological Ego, not only as a pole of identity but above all as a set of habits, i.e. a series of synthesis passively persisting in his own personal life; 3 ) the relation of transcendental subjectivity to the life-world, as the world of intuition and immediate experience, and the ultimate ground of meaning.
\end{abstract}

